\title{
Loudness and loudness discrimination
}

\author{
SCOTT PARKER \\ The American University, Washington, D.C. 20016 \\ and \\ BRUCE SCHNEIDER \\ University of Toronto, Toronto, Ontario, Canada MSS IAI
}

\begin{abstract}
A model is developed which holds that pure-tone intensity discrimination and suprathreshold loudness judgments are based on the same sensory representation. In this model, loudness is a power function of sound intensity. When two tones are presented sequentially, each gives rise to a loudness value along the sensory continuum. In intensity-discrimination experiments, threshold is reached when the loudness difference between the tones exceeds a criterial value. For suprathreshold presentations of tone pairs, judgments of loudness differences are based on the loudness difference between the two tones. The model is shown to accord well with data from both classes of experiments.
\end{abstract}

Fechner proposed, in 1860 , that the increment in sensation corresponding to a just noticeable difference (jnd) could be used as a unit of sensation. Therefore, if one were to start at threshold and mark off successive jnds, each jnd would increment the sensation value (S) by the same amount. According to this formulation, then, the sensation value of a stimulus is directly proportional to the cumulative jnd value; that is, if stimulus $\mathrm{X}$ is $\mathrm{n}$ jnds above threshold, its sensation value is

$$
\mathrm{S}=\mathrm{cn} \text {, }
$$

where $\mathrm{c}$ is a scale constant corresponding to the choice of unit sensation. To relate sensation to intensity, Fechner seized upon Weber's law $(\Delta I=k I$, where $I$ is the intensity of the standard stimulus, $\mathrm{k}$ is a constant of proportionality, and $\Delta \mathrm{I}$ is the increment in intensity necessary to evoke a jnd in sensation). Using Weber's law, it can be shown (e.g., Falmagne, 1974) that the number of jnds above threshold is

$$
\mathrm{n}=\mathrm{a} \log (\mathrm{I})+\mathrm{b} .
$$

By simple substitution, then, we arrive at Fechner's law, namely,

$$
\mathrm{S}=\mathrm{a}^{\prime} \log (\mathrm{I})+\mathrm{b}^{\prime},
$$

where $a^{\prime}=a c$ and $b^{\prime}=b c$.

The results of a large number of studies using

This study was supported in part by a National Research Council grant to B. Schneider. Reprints may be obtained from Scott Parker, Department of Psychology, The American University, Washington, D.C. 20016. direct scaling methods (see Marks, 1974, or Stevens, 1975 , for a review) have yielded power functions relating magnitude estimates to physical intensity, suggesting that a power law,

$$
\mathrm{S}=\mathrm{c}^{\prime} \mathbf{I}^{\mathrm{m}},
$$

might be a more appropriate choice to describe the relationship between sensation magnitude and intensity ( $c^{\prime}$ and $m$ are constants). The power-law formulation for loudness has also been found to hold for category estimation (Marks, 1968), judgments of loudness differences and similarities (Parker \& Schneider, 1974), and paired comparisons of loudness differences (Schneider, Parker, \& Stein, 1974). Thus, the result of Fechnerian integration (using Weber's law to describe the discrimination function) differs markedly from the results obtained using the scaling techniques mentioned above. This has led many investigators to abandon Fechner's law.

If Fechner's law is incorrect, it implies that either his assumption (jnds are units of sensation) is incorrect or Weber's law is wrong. Stevens (1962), for one, has contended that Fechner's assumption is incorrect. He argues that a just noticeable increase in stimulus intensity induces not a constant increment but, rather, a constant proportional increase in sensation. This latter assumption, combined with Weber's law, will yield a power function representation for sensation. However, the results of a number of modern psychophysical studies (cited below) have shown that Weber's law is in error. Therefore, it is still possible, as Falmagne (1974) has pointed out, that Fechner's assumption is consistent with a power-function representation of loudness. Below we outline and test three models that potentially can resolve the conflict 
between Fechner's idea and Stevens' power law. These three models were originally formalized by Falmagne (1974).

\section{POWER FUNCTION DISCRIMINATION MODELS}

In the usual Fechnerian model, the sensory representation is obtained from the discrimination data. For the three models considered here, we will reverse that order; that is, we will try to predict the discrimination data assuming that a power function governs loudness $-\mathrm{L}=\left(\mathrm{I} / \mathrm{I}_{\mathrm{o}}\right)^{\mathrm{m}}$, where $\mathrm{I}$ is sound intensity, $\mathrm{I}_{\mathrm{O}}$ is the reference sound intensity $\left(10^{-16} \mathrm{~W} / \mathrm{cm}^{2}\right)$, and $\mathrm{m}$ is a constant. ${ }^{1}$

\section{Model 1. Loudness Difference}

If two sound intensities are presented in a discrimination paradigm (such as a two-alternative forced-choice procedure), we assume that the probability of a correct response, $p(C)$, is a function of the extent to which the tones differ in loudness, that is, $p(C)=f\left(L_{i}-L_{j}\right)$, where $\mathrm{f}$ is a monotone increasing function for $.5<\mathrm{p}(\mathrm{C})<1$. If loudness is a power function of intensity, a simple substitution yields

$$
\mathrm{p}(\mathrm{C})=\mathrm{f}\left[\left(\mathrm{I}_{\mathrm{i}} / \mathrm{I}_{\mathrm{o}}\right)^{\mathrm{m}}-\left(\mathrm{I}_{\mathrm{j}} / \mathrm{I}_{\mathrm{o}}\right)^{\mathrm{m}}\right]
$$

In defining threshold, a constant response criterion is usually employed; that is, threshold is reached when $p(C)=p_{t}$, where $p_{t}$ is some criterial probability value. Since $f$ is monotone increasing, we can solve Equation 5 for the value of $\left(\mathrm{I}_{\mathrm{i}} / \mathrm{I}_{\mathrm{o}}\right)^{\mathrm{m}}-\left(\mathrm{I}_{\mathrm{j}} / \mathrm{I}_{\mathrm{o}}\right)^{\mathrm{m}}$ such that $\mathrm{f}\left[\left(\mathrm{I}_{\mathrm{i}} / \mathrm{I}_{\mathrm{o}}\right)^{\mathrm{m}}-\left(\mathrm{I}_{\mathrm{j}} / \mathrm{I}_{\mathrm{o}}\right)^{\mathrm{m}}\right]=\mathrm{p}_{\mathrm{t}}$. Let that value of $\left(\mathrm{I}_{\mathrm{i}} / \mathrm{I}_{\mathrm{o}}\right)^{\mathrm{m}}$ $-\left(I_{j} / I_{o}\right)^{m}$ be called the threshold loudness difference $\left(\Delta \mathrm{L}_{t}\right)$. The model states that threshold is reached when some criterial loudness difference, $\Delta \mathrm{L}_{\mathrm{t}}$, occurs.

\section{Model 2. Loudness Ratio with Additive Constant}

Rather than assuming that discrimination is based on loudness differences, we could equally well assume that it is based on loudness ratios, that is,

$$
\begin{aligned}
\mathrm{p}(\mathrm{C}) & =\mathrm{g}\left\{\left[\left(\mathrm{I}_{\mathrm{i}} / \mathrm{I}_{\mathrm{o}}\right)^{\mathrm{m}}+\mathrm{k}\right] /\left[\left(\mathrm{I}_{\mathrm{j}} / \mathrm{I}_{\mathrm{o}}\right)^{\mathrm{m}}+\mathrm{k}\right]\right\} \\
& =\mathrm{h}\left\{\log \left[\left(\mathrm{I}_{\mathrm{i}} / \mathrm{I}_{\mathrm{o}}\right)^{\mathrm{m}}+\mathrm{k}\right]-\log \left[\left(\mathrm{I}_{\mathrm{j}} / \mathrm{I}_{\mathrm{o}}\right)^{\mathrm{m}}+\mathrm{k}\right]\right\} .
\end{aligned}
$$

The constant, $k$, is included to give greater generality to the model and to permit estimation of the exponent, $m$. In this model, threshold is reached when $p(C)=p_{t}$, our criterial probability value. Again, $h$ is monotone increasing. Let $\Delta \mathrm{R}_{\mathrm{t}}$ be the value of $\left\{\log \left[\left(\mathrm{I}_{\mathrm{i}} / \mathrm{I}_{\mathrm{o}}\right)^{\mathrm{m}}+\mathrm{k}\right]\right.$ $\left.-\log \left[\left(\mathrm{I}_{\mathrm{j}} / \mathrm{I}_{\mathrm{o}}\right)^{\mathrm{m}}+\mathrm{k}\right]\right\}$ for which $\mathrm{h}\left\{\log \left[\left(\mathrm{I}_{\mathrm{i}} / \mathrm{I}_{\mathrm{o}}\right)^{\mathrm{m}}+\mathrm{k}\right]-\right.$ $\left.\log \left[\left(\mathrm{I}_{\mathrm{j}} / \mathrm{I}_{\mathrm{O}}\right)^{\mathrm{m}}+\mathrm{k}\right]\right\}=\mathrm{p}_{\mathrm{t}}$. This model states that threshold is reached when some criterial loudness ratio, $\Delta \mathrm{R}_{\mathrm{t}}$, occurs.

\section{Model 3. Loudness Ratio}

Model 3 is the same as Model 2 without the additive constant, k. Hence,

$$
p(C)=h\left[\log \left(I_{i} / I_{o}\right)^{m}-\log \left(I_{j} / I_{o}\right)^{m}\right]
$$

and $\Delta R=\log I_{i}^{m}-\log I_{j}^{m}$. This model states that threshold is reached when $p_{t}=h\left(\Delta R_{t}\right)$. Note that in this model it is not possible to estimate the exponent since $\Delta R$ is constant if and only if $I_{i} / I_{j}$ is constant. However, since this model is, as Stevens (1962) pointed out, equivalent to Weber's law, we can still make some testable predictions.

In the remainder of the paper we will evaluate which of the three models best accounts for the results on studies on loudness discrimination of $1,000-\mathrm{Hz}$ or near $1,000-\mathrm{Hz}$ tone bursts presented monaurally. The parameters of these studies are given in Table 1. In each of the studies reviewed below, the sound intensity of the standard stimulus, $I_{s}$, was varied over a fairly wide range using a two-interval or a two-alternative forced-choice procedure. In most cases, we read values of $\Delta \mathrm{I}$ from the published graphs. Only cases in which the standard or comparison stimulus equaled or exceeded $30 \mathrm{~dB}$ SPL are reported here. The reason for this decision is that many studies indicate a change in the power function representation for loudness at intensity values $(I<30 \mathrm{~dB})$ close to absolute threshold (e.g., Scharf \& Stevens, 1961). We felt that including these near-threshold values might distort the representation for loudness for intensity values above $30 \mathrm{~dB}$. Consequently, they are not reported here.

In the experiments reviewed here, for each $I_{s}$ the intensity of the comparison stimulus, $I_{c}$, which was necessary to reach the difference threshold, was determined. ${ }^{2}$ This difference threshold is called $\Delta \mathbf{I}=$ $I_{c}-I_{s}$. Following one of the conventions of the audition literature, $\Delta \mathrm{I}$ in decibels is defined as $10 \mathrm{log}$ $\left(1+\Delta \mathrm{I} / \mathrm{I}_{\mathrm{S}}\right)=10 \log \left(\mathrm{I}_{\mathrm{c}} / \mathrm{I}_{\mathrm{s}}\right)$.

\section{PARAMETER ESTIMATION}

\section{Model 1. Loudness Difference}

According to the loudness difference model, $\Delta \mathrm{L}=$ $\left(I_{c} / I_{o}\right)^{m}-\left(I_{s} / I_{o}\right)^{m}$ is constant for the value of $m$ which characterizes the growth of loudness as a function of intensity. For each of the studies here, we have the paired values of $I_{s}$ and $I_{c}$. Hence, we need to determine the value of $m$ which most nearly satisfies the condition that

$$
\Delta \mathrm{L}_{1}=\Delta \mathrm{L}_{2}=\Delta \mathrm{L}_{3} \ldots=\Delta \mathrm{L}_{\mathrm{i}}=\ldots=\Delta \mathrm{L}_{\mathrm{n}},
$$

where $\Delta \mathrm{L}_{\mathrm{i}}$ refers to the $\mathrm{i}^{\text {th }}$ threshold's loudness difference in a particular study. Note that this condition is 
Table 1

\begin{tabular}{|c|c|c|c|c|}
\hline & $\begin{array}{l}\text { Threshold Criterion } \\
\text { (Percent Correct) }\end{array}$ & $\begin{array}{c}\text { Intensity Range } \\
\text { (in Decibels) }\end{array}$ & $\begin{array}{c}\text { Number of Stimuli } \\
\geqslant 30 \mathrm{~dB}\end{array}$ & $\begin{array}{l}\text { Tone Duration } \\
\text { (in Milliseconds) }\end{array}$ \\
\hline Campbell and Lasky (1967) & 75 & $10-90$ & 7 & 20,1000 \\
\hline Jesteadt, Wier, \& Green (1977) & 71 & $5-80$ & 2 & 500 \\
\hline McGill and Goldberg (1968a) & 75 & $0-80$ & 5 & 150 \\
\hline McGill and Goldberg (1968b) & 75 & $4-70$ & 5 & 20 \\
\hline Penner et al. $(1974)^{*}$ & 75 & $30-75$ & 6 & 100 \\
\hline Schacknow and Raab (1973) & 75 & $30-75$ & 3 & 250 \\
\hline Viemeister $(1972)^{* *}$ & 76 & $30-85$ & 3 & 160 \\
\hline
\end{tabular}

*Binaural presentation. **Tone-burst frequency was $950 \mathrm{~Hz}$.

satisfied when the variance of the $\Delta \mathrm{Ls}$ is zero. Therefore, it seems reasonable to determine the value of $m$ that minimizes that variance. The variance of $\Delta \mathrm{L}$ is at a minimum when

$$
\Sigma \Delta \mathrm{L}^{2}-(\Sigma \Delta \mathrm{L})^{2} / \mathrm{n}
$$

is at a minimum. Since the absolute size of this quantity will vary with $\mathrm{m}$, Expression 9 was first normalized by dividing through by $\Sigma \Delta \mathrm{L}^{2}$ to yield

$$
1-(\Sigma \Delta \mathrm{L})^{2} / \mathrm{n} \Sigma \Delta \mathrm{L}^{2} \text {. }
$$

Note that $(\Sigma \Delta \mathrm{L})^{2} / \mathrm{n} \Sigma \Delta \mathrm{L}^{2}$ is the proportion of the total sum of squares $\left(\Sigma \Delta \mathrm{L}^{2}\right)$ due to the mean $(\Sigma \Delta \mathrm{L} / \mathrm{n})$ (see Graybill, 1961); hence, when all $\Delta \mathrm{Ls}$ are equal to their mean, $(\Sigma \Delta \mathrm{L})^{2} / \mathrm{n} \Sigma \Delta \mathrm{L}^{2}=1$ and Expression 10 equals zero. ${ }^{3}$ In the present analysis, an iterative procedure was used to determine the value of $m$ that minimized the value of Expression 10. The values of $\mathrm{m}$ determined for each of the studies reviewed are shown in column 1 of Table 2 . Note that $m$ varies from .07 to .15 , with a mean value across studies of .11 .

The value of the exponent, $\mathrm{m}$, and the values of $I_{S}$ and $I_{c}$ can be used to generate estimates of the values of $\Delta \mathrm{L}_{\mathrm{t}}$. Column 2 of Table 2 gives the mean estimate of $\Delta \mathrm{L}_{\mathrm{t}}$ for each of these experiments. ${ }^{4}$ The value of the threshold loudness difference varies

Table 2

\begin{tabular}{llll}
\hline & $\mathrm{m}$ & $\Delta \mathrm{L}_{\mathrm{t}}$ & $\mathrm{V}$ \\
\hline McGill and Goldberg (1968a) & .13 & .17 & .9601 \\
McGill and Goldberg (1968b) & .15 & .35 & .9836 \\
Campbell and Lasky (1967) & & & \\
$\quad$ 20-Msec Duration & .07 & .13 & .9964 \\
$\quad$ 1,000-Msec Duration & .08 & .06 & .9958 \\
Viemeister (1972) & .11 & .08 & .9995 \\
Schacknow and Raab (1973) & & & \\
$\quad$ Subject 1 & .13 & .10 & .9741 \\
$\quad$ Subject 2 & .08 & .04 & .9596 \\
Penner et al. (1974) & .15 & .27 & .9798 \\
Jesteadt et al. (1977) & .09 & .05 & 1.0000 \\
\hline
\end{tabular}

Note-V $=$ variance due to mean. $\Delta L_{t}$ is given in arbitrary units. from a low of .04 to a high of .35. Column 3 gives the proportion of total sum of squares due to the mean. Recall that a value of 1.00 indicates that the variance is zero. Thus, in each of these experiments, it was possible to select a value of $m$ which yielded $\Delta$ Ls that were nearly equal.

\section{Model 2. Loudness Ratio with Additive Constant}

In this model, we also expect that Equation 8 (substituting $\Delta \mathrm{R}$ for $\Delta \mathrm{L}$ ) will hold when $\Delta \mathrm{R}=$ $\log \left[\left(\mathrm{I}_{\mathrm{c}} / \mathrm{I}_{\mathrm{o}}\right)^{\mathrm{m}}+\mathrm{k}\right]-\log \left[\left(\mathrm{I}_{\mathrm{s}} / \mathrm{I}_{\mathrm{o}}\right)^{\mathrm{m}}+\mathrm{k}\right]$. Again, Equation 8 will be best satisfied if we minimize Equation 10 . Accordingly, values of $\mathrm{m}$ and $\mathrm{k}$ were found using an iterative process that minimized Equation 10. These values are shown in Table 3 along with the average $\Delta R$ value and the proportion of total sum of squares due to the mean. ${ }^{5}$ Values of $\mathrm{k}$ greater than $10^{8}$ were not explored because such large values are unlikely to be psychologically meaningful.

A comparison of Tables 2 and 3 shows that both models, with the exception of the McGill and Goldberg (1968a) study, account for approximately the same proportion of sum of squares. That is to say, parameters that equally well satisfy Condition 8 can be found for both models. Note that the ratio model provided a slightly better fit to the McGill and Goldberg (1968a) study. However, to provide this better fit, an exponent of .75 was required, an exponent that is 5 times greater than any of the other exponents estimated by the two models. A comparison of Tables 2 and 3 also shows that, with the exception of the McGill and Goldberg (1968a) study, the exponents estimated by the two models are approximately comparable. ${ }^{6}$ Note, however, the wide variation in the estimate of the parameter $\mathrm{k}$.

\section{Model 3. Loudness Ratio}

This model is identical to Model 2 without the parameter $k$. However, without the parameter $k$, Equation 10 cannot be used to estimate $\mathrm{m}$, since $\mathrm{m}$ appears as a multiplier in both the numerator and denominator and hence cancels out. However, Equation 10 can still be used to estimate the extent to which all the $\Delta R$ s are equivalent. The proportions of variance accounted for by the mean are .8072 , 
Table 3

\begin{tabular}{llccc}
\hline & $\mathrm{m}$ & $\mathrm{k}$ & $\Delta \mathrm{R}$ & $\mathrm{V}$ \\
\hline McGill and Goldberg (1968a) & .75 & $4.44 \times 10^{2}$ & $7.04 \times 10^{-2}$ & .9952 \\
McGill and Goldberg (1968b) & .18 & $5.15 \times 10$ & $3.92 \times 10^{-3}$ & .9839 \\
Campbell and Lasky (1967) & & & & \\
20-Msec Duration & .07 & $4.23 \times 10$ & $1.39 \times 10^{-4}$ & .9964 \\
1,000-Msec Duration & .08 & $1.93 \times 10$ & $1.39 \times 10^{-4}$ & .9958 \\
Viemeister (1972) & .13 & $3.15 \times 10$ & $1.52 \times 10^{-3}$ & 1.0000 \\
Schacknow and Raab (1973) & & & & .9741 \\
$\quad$ Subject 1 & .12 & $7.15 \times 10^{5}$ & $5.80 \times 10^{-9}$ & .9596 \\
$\quad$ Subject 2 & .08 & $3.37 \times 10^{6}$ & $4.80 \times 10^{-9}$ & .9798 \\
Penner et al. (1974) & .15 & $1.30 \times 10^{7}$ & $9.90 \times 10^{-5}$ & 1.0000 \\
Jesteadt et al. (1977) & .10 & $9.30 \times 10$ & $2.43 \times 10^{-4}$ & \\
\hline
\end{tabular}

Note-V $=$ variance due to mean. $\Delta R$ is given in arbitrary units.

$.7959, .9065, .9113, .7803, .8585, .9196, .8234, .8612$ for the studies in the order in which they appear in Table 2. It is apparent that equality of the $\Delta \mathrm{Rs}$ does not hold up for the simple ratio model without the additive constant.

\section{Predicted Thresholds}

A further comparison of the three models can be made in terms of their predicted threshold increments $(\hat{\Delta} \mathrm{I})$ at each of the intensity values. Let $\hat{\mathrm{I}}_{\mathrm{c}}$ be the predicted comparison intensity. For Model 1

$$
\hat{\Delta} \mathrm{I}=\hat{\mathrm{I}}_{\mathrm{c}}-\mathrm{I}_{\mathrm{s}}=\mathrm{I}_{\mathrm{o}}\left[\Delta \mathrm{L}+\left(\mathrm{I}_{\mathrm{s}} / \mathrm{I}_{\mathrm{o}}\right)^{\mathrm{m}}\right]^{1 / \mathrm{m}}-\mathrm{I}_{\mathrm{s}} ;
$$

for Model 2

$$
\hat{\Delta} \mathrm{I}=\hat{\mathrm{I}}_{\mathrm{c}}-\mathrm{I}_{\mathrm{s}}=\mathrm{I}_{\mathrm{o}}\left\{10^{\Delta \mathrm{R}}\left[\left(\mathrm{I}_{\mathrm{s}} / \mathrm{I}_{\mathrm{o}}\right)^{\mathrm{m}}+\mathrm{k}\right]-\mathrm{k}\right\}^{1 / \mathrm{m}}-\mathrm{I}_{\mathrm{s}} ;
$$

and for Model 3

$$
\hat{\Delta} \mathrm{I}=\hat{\mathrm{I}}_{\mathrm{c}}-\mathrm{I}_{\mathrm{s}}=\left(10^{\Delta \mathrm{R} / \mathrm{m}}-1\right) \mathrm{I}_{\mathrm{s}}=\mathrm{kI} \mathrm{s}_{\mathrm{s}}
$$

Note that the prediction for Model 3 is Weber's law.

Models 1 and 2, if theMcGill and Goldberg (1968a) study is excluded, make almost identical predictions. ${ }^{7}$ If, in both models, predicted $\Delta \mathrm{Is}$ are expressed in decibels, the correlation coefficient between the two sets of predictions is $\mathbf{9 9 9 7 . ~ C o n s e q u e n t l y , ~ t h e ~ r e l a - ~}$ tionship between the predicted $\Delta \mathrm{I}$ s and the actual $\Delta \mathrm{Is}$ is shown only for Model 1 in Figure 1. Figure 1 shows that the relationship between predicted and obtained values for the power function discrimination model is quite good. Figure 2 shows the predictions of Model 3, the power function ratio model with no additive constant. As Equation 13 shows, this prediction is equivalent to Weber's law. To obtain these predictions, the average value of $\Delta \mathrm{I} / \mathrm{I}$ was determined in each study. Note that the simple power function ratio model (Weber's law) does rather poorly, as we might expect, since none of the discrimination studies reported here support Weber's law.
At this point, it is reasonable to consider the McGill and Goldberg (1968a, 1968b) "near miss" to Weber's law. If Weber's law were correct, then $\Delta \mathrm{I}=\mathrm{kI}$ and $\log (\Delta \mathrm{I})=\log (\mathrm{I})+\log (\mathrm{k})$. However, when these authors plotted $\log (\Delta \mathrm{I})$ vs. $\log (\mathrm{I})$, they found that although the function was essentially linear, the slope was smaller than 1. Thus, they argued that the relationship between $\Delta \mathrm{I}$ and $\mathrm{I}$ was

$$
\log (\Delta I)=n \log (I)+\log (k),
$$

where $n \neq 1$. There are several problems with the McGill and Goldberg formulation. First, this formulation is incompatible with any of the three models proposed here. For example, in Model 1, we propose that

$$
\mathrm{p}(\mathrm{I}+\Delta \mathrm{I}, \mathrm{I})=\mathrm{f}[\mathrm{L}(\mathrm{I}+\Delta \mathrm{I})-\mathrm{L}(\mathrm{I})]
$$

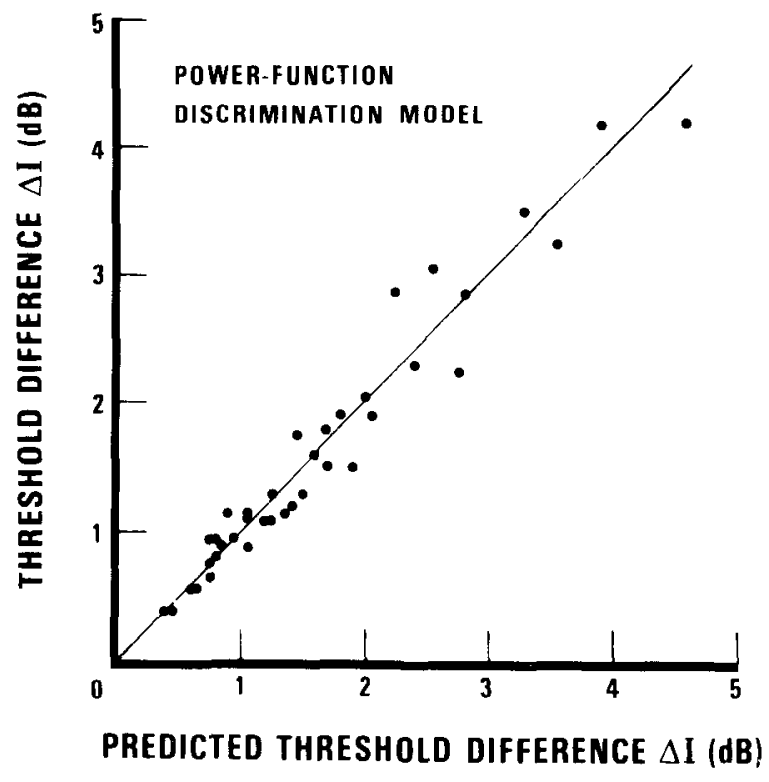

Figure 1. Threshold difference $(\Delta I)$ in decibels as a function of the predicted threshold difference (also in decibels) for the power function discrimination model. 


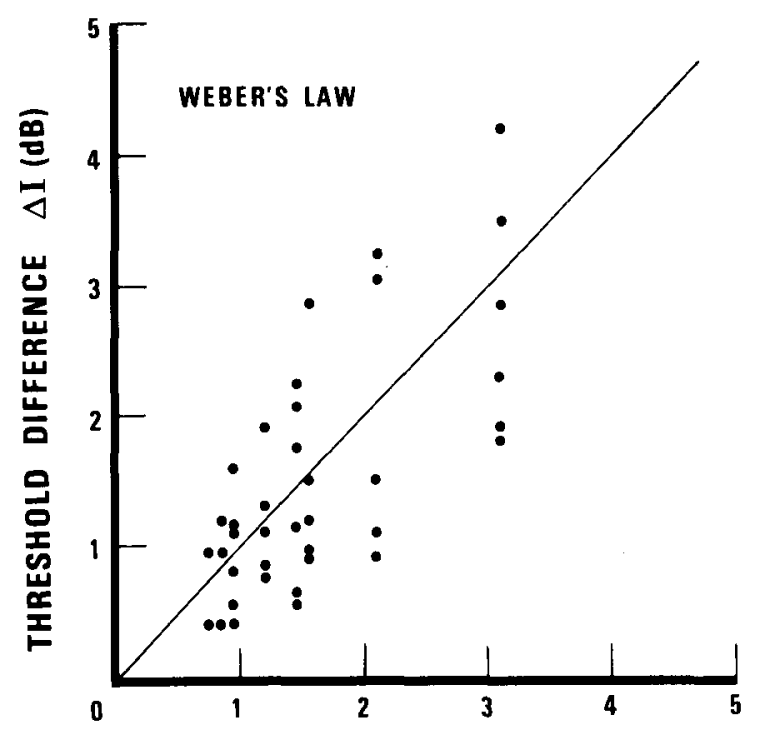

PREDICTED THRESHOLD DIFFERENCE $\triangle \mathrm{I}$ (dB)

Figure 2. Threshold difference $(\Delta I)$ in decibels as a function of the predicted threshold difference based on Weber's law.

that is, the probability with which $I$ and $I+\Delta I$ are discriminated is a function of $[\mathrm{L}(\mathrm{I}+\Delta \mathrm{I})-\mathrm{L}(\mathrm{I})]$. Falmagne (1971) has shown that Equation 15 is valid only if differential thresholds are permutable. Let $\pi$ be $\mathrm{p}(\mathrm{I}+\Delta \mathrm{I}, \mathrm{I})$. Then $\Delta_{\pi} \mathrm{I}$ is the amount by which $\mathrm{I}$ is incremented, such that $\mathrm{I}$ and $\mathrm{I}+\Delta_{\pi}(\mathrm{I})$ are discriminated with probability $\pi$. Now, suppose we increment I $+\Delta_{\pi}(\mathrm{I})$ by $\Delta_{\pi^{\prime}}\left[\mathrm{I}+\Delta_{\pi}(\mathrm{I})\right]$ so that I $+\Delta_{\pi}(\mathrm{I})$ and I $+\Delta_{\pi}(\mathrm{I})$ $+\Delta_{\pi^{\prime}}\left[\mathrm{I}+\Delta_{n}(\mathrm{I})\right]$ are discriminated with probability $\pi^{\prime}$. Permutability of differential thresholds means that

$$
\Delta_{\pi^{\prime}}\left[\Delta_{\pi}(\mathrm{I})+\mathrm{I}\right]+\Delta_{\pi}(\mathrm{I})=\Delta_{\pi}\left[\Delta_{\pi^{\prime}}(\mathrm{I})+\mathrm{I}\right]+\Delta_{\pi^{\prime}}(\mathrm{I})
$$

that is, adding $\Delta_{\pi^{\prime}}\left[\Delta_{\pi}(\mathrm{I})+\mathrm{I}\right]$ to $\Delta_{\pi}(\mathrm{I})+\mathrm{I}$ is the same as first determining $\Delta_{\pi^{\prime}}(\mathrm{I})+\mathrm{I}$ and then adding $\Delta_{\pi}\left[\Delta_{\pi^{\prime}}(\mathrm{I})\right.$ $+1]$. Note that $\pi$ and $\pi^{\prime}$ need not be equal. For example, suppose that $\pi=.7$ and $\pi^{\prime}=.85$. Equation 16 says that if we increment I by an amount $\Delta .7$ (I), such that I and I $+\Delta_{.7}$ (I) are discriminated $70 \%$ of the time, and then increment $\mathrm{I}+\Delta_{.7}$ (I) by amount $\Delta_{.85}\left[\mathrm{I}+\Delta_{.7}(\mathrm{I})\right]$, the result would be the same as if we proceeded in the reverse order by finding $\mathrm{I}+\Delta_{.85}(\mathrm{I})$ and then $\Delta_{.7}\left[\mathrm{I}+\Delta_{.85}(\mathrm{I})\right]$. It is easy to show that this property cannot hold if the near miss describes the discrimination data, for, in that case, $\Delta_{\pi}(\mathrm{I})=\mathrm{k}(\pi) \mathrm{I}^{\mathrm{n}}$, with $k(\pi)>0$ and $k(\pi)$ strictly increasing in $\pi$, as required by Equation 15 . Substituting into Equation 16 yields

$$
\begin{aligned}
& \mathrm{k}\left(\pi^{\prime}\right)\left[\mathrm{k}(\pi) \mathrm{I}^{\mathrm{n}}+\mathrm{I}\right]^{\mathrm{n}}+\mathrm{k}(\pi) \mathrm{I}^{\mathrm{n}} \\
& =\mathrm{k}(\pi)\left[\mathrm{k}\left(\pi^{\prime}\right) \mathrm{I}^{\mathrm{n}}+\mathrm{I}\right]^{\mathrm{n}}+\mathrm{k}\left(\pi^{\prime}\right) \mathrm{I}^{\mathrm{n}} .
\end{aligned}
$$

If we assume that this equation holds for all intensities
I, and some $\pi, \pi^{\prime}$, with $\pi \neq \pi^{\prime}$, then it must be that $\mathrm{n}=1$. Otherwise, the equation does not hold. ${ }^{8}$ Hence, if Equation 17 is to hold, Weber's law $(n=1)$ must apply. If the near miss holds $(n \neq 1)$, then no loudness discrimination model of the form $\pi=h\left[u\left(I_{i}\right)\right.$ $\mathrm{u}\left(\mathrm{I}_{\mathrm{j}}\right)$ ] can hold. Note that this excludes Model 2 as well. However, it can be shown that the near miss to Weber's law will closely approximate the predictions made by Models 1 and 2. The reason for this is that the near-miss law is a good approximation to the discrimination function we have derived for the loudness discrimination model. From Equation $11, \mathrm{I}_{\mathrm{c}}=\mathrm{I}_{\mathrm{o}}[\Delta \mathrm{L}+$ $\left.\left(I_{s} / I_{o}\right)^{m}\right]^{1 / m}$. Dividing by $I_{s}$ yields $I_{c} / I_{s}=\left(\Delta L I_{o}^{m} I_{s}^{-m}\right.$ $+1)^{1 / m}$. Approximating the right-hand side of this equation by the first two terms of its Taylor series expansion yields $\mathrm{I}_{\mathrm{c}} / \mathrm{I}_{\mathrm{s}} \cong 1+(1 / \mathrm{m}) \Delta \mathrm{LI} \mathrm{I}_{\mathrm{o}}^{\mathrm{m}} \mathrm{I}_{\mathrm{s}}^{-\mathrm{m}}$ or $\mathrm{I}_{\mathrm{c}} \cong$ $I_{s}+(1 / m) \Delta L I_{0}^{m} I_{s}^{1-m}$. Finally, we obtain $I_{c}-I_{s} \cong$ $(1 / \mathrm{m}) \Delta \mathrm{LI}_{\mathrm{o}}^{\mathrm{m}} \mathrm{I}_{\mathrm{s}}^{1-\mathrm{m}}$, which is the near-miss relationship. Note that the near-miss exponent is 1 minus the power function exponent in the loudness discrimination model. Hence, it is not surprising that the near-miss exponents are usually found to be on the order of .9 . Hence, it seems more appropriate to consider Equation 11 as the appropriate description of the discrimination function and the near-miss law as an approximation. In this way, the power law remains compatible with the discrimination data.

\section{DISCUSSION}

Three power-function models of loudness discrimination were explored. Model 3, the simple loudness ratio model, where $\mathrm{I}_{\mathrm{c}}^{\mathrm{m}} / \mathrm{I}_{\mathrm{s}}^{\mathrm{m}}$ is constant at threshold, performs poorly in two areas. First, $I_{c} / I_{s}$ is not constant at threshold, as indicated by the relatively low proportion of the sum of squares accounted for by the mean. Second, as Stevens (1962) pointed out, this model predicts Weber's law. And, as Figure 2 shows, Weber's law cannot account for the loudness discrimination data.

This leaves two power-function models, Model 1, which is a loudness discrimination model, and Model 2, which is a generalized loudness ratio model. Both do equally well with respect to our two criteria. First, the extent to which Model 1 maintains a constant loudness difference $(\Delta \mathrm{L})$ is the same as the extent to which Model 2 maintains a constant loudness ratio $(\Delta R)$, as indicated by column 3 in Table 2 and column 4 in Table 3 . Second, both do equally well in predicting the discrimination data. However, Model 2 can accomplish this only at the expense of a great variation in the parameter $k$. An examination of the estimated value of the constant $k$ (see Table 3 ) in each of the studies shows that $k$ ranges from 19.3 to $1.30 \times 10^{7}$. Although several arguments have been advanced for a power law with an additive constant, k (McGill, 1960), none of these formulations would predict a range of $\mathrm{k}$ values of this extent. However, 
the observed variability of the estimate of the parameter $\mathrm{k}$ may be due to the fact that no near-threshold intensities were employed. It is quite possible that, if near-threshold intensities were employed, $\mathrm{k}$ would be more tightly constrained. In any event, the wide variation in $k$ poses some difficulties for the generalized ratio model.

Model 1, on the other hand, with but a single parameter, provides as good a fit to Condition 8 as Model 2 with two parameters. Furthermore, we have reason to believe that Model 2 provides an equally good fit simply because an appropriate choice of $\mathrm{k}$ can yield the same prediction as Model 1.' Generally speaking, if a two-parameter model can do no better than a one-parameter model, the one-parameter model is preferred. Hence, the results obtained here favor Model 1, the loudness discrimination model.

It is interesting to note that Mansfield (1976), in deriving a model for visual adaptation and brightness, arrives at a near-miss law (over a range of about $5 \log$ units) for intensity discrimination for the brightnesses of lights. Furthermore, the data from his study and those of Barlow (1957) and Blackwell (1946) support a near-miss relationship with an exponent of about .68. As we have shown earlier, data that fit a near-miss model will also fit the sensory discrimination model (Model 1) proposed here. The brightness exponent typically found in these experiments is on the order of .33, that is, 1 minus the near-miss exponent. Thus, there is some indication that Model 1 may apply to brightness and brightness discrimination. However, how generally the model might apply in vision is difficult to determine, since changes in the state of adaptation, etc., can alter the form of the relationship between $\Delta \mathrm{I}$ and I (e.g., Cornsweet \& Pinsker, 1965; Hood \& Finkelstein, 1979). Thus, we would expect that changes that affect the relationship between $\Delta \mathrm{I}$ and $\mathrm{I}$ would also alter the psychophysical function relating brightness to intensity. These conditions could be investigated to test the discrimination model for visual brightness.

With respect to loudness, we can examine certain features of the discrimination model to see whether these features have a reasonable psychological interpretation. To predict thresholds, the loudness discrimination model requires two parameters, $m$, the exponent of the power function, and $\Delta \mathrm{L}$, the size of the threshold loudness difference. Table 2 shows that there is some variation in both the values of the exponents and the values of the critical loudness differences across studies. A logical question is whether any of this variation can be attributed to differences among the parameters of the studies. An examination of Table 1 shows that the durations of the tone bursts varied from study to study. Therefore, Figure 3 examines the relationship between exponent and tone-burst duration. An examination of Fig-

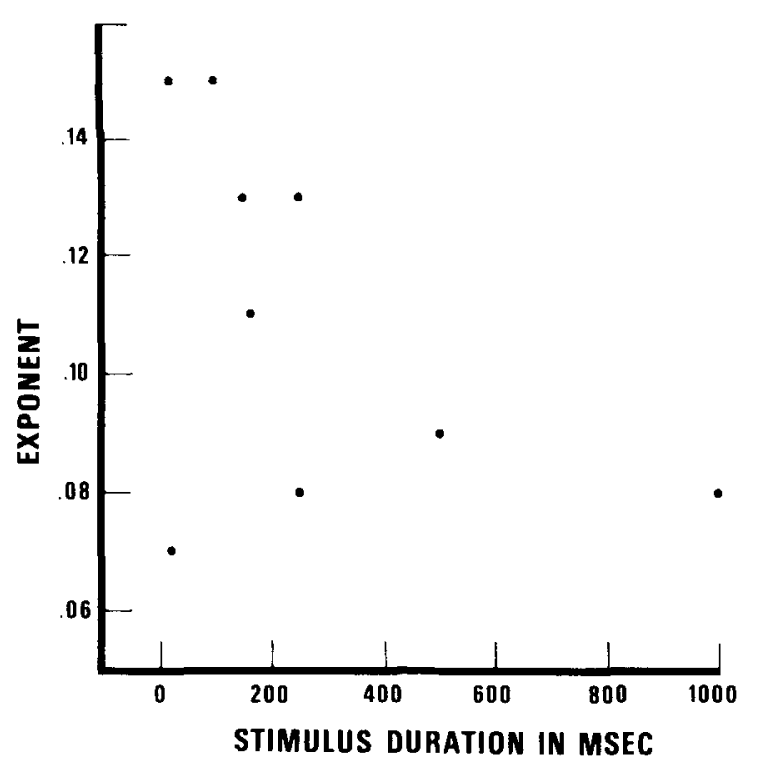

Figure 3. Exponents of the power function discrimination model as a function of tonal duration in milliseconds.

ure 3 shows no strong systematic relationship between exponent and duration; however, there may be a slight tendency for the higher exponents to be associated with the shorter durations. This tendency becomes more pronounced if the two studies using 20 -msec tones are ignored. Figure 4 , on the other hand, shows that the threshold loudness difference $\left(\Delta \mathrm{L}_{t}\right)$ decreases rapidly with increasing duration. Both Luce and Green's (1972) timing model and McGill's (1967) counting model would predict a variation of this sort. The fact that both $\mathrm{m}$ and $\Delta \mathrm{L}$ refer to specifiable sensory processes, and the fact that $\Delta \mathrm{L}$ varies in the expected way with tone duration while $\mathrm{m}$ does not, lends support to the loudness difference model. This kind of specifiability leads more readily to tests of the model in terms of more basic sensory processis.

Another virtue of the loudness difference model is that it provides a direct link between threshold and suprathreshold experiments. In both cases, the presentation of two signals differing in intensity gives rise to a loudness difference, $\Delta \mathrm{L}$, which can be expressed as the difference between power-functionally transformed sound intensities. Thus, according to the model, the same sensory processes operate at threshold and suprathreshold levels. It is interesting to note that average exponents obtained in the present experiments are not too far different from the exponents obtained from nonmetric analyses of judgments of loudness differences [.13, Parker \& Schneider, 1974; .13, Schneider et al., 1974), judgments of loudness similarity (.12, Parker \& Schneider, 1974), judgments of loudness ratios $[.11$ and .07 , Schneider, Parker, Farrell, \& Kanow, 1976; .11, 


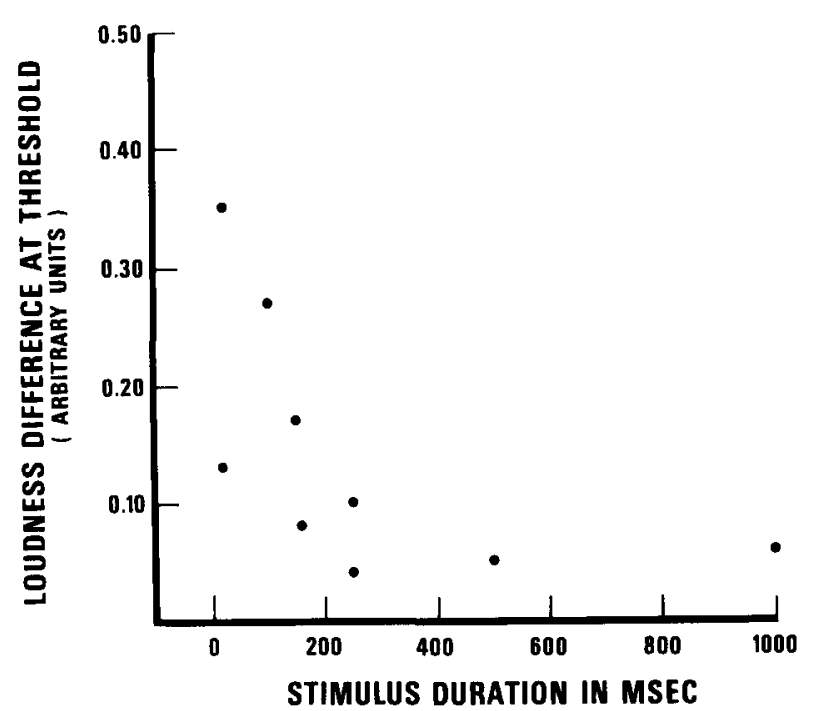

Figure 4. Loudness difference at threshold as a function of tonal duration in milliseconds.

.11 , and .22, Richards, 1974 (analyzed in Schneider et al., 1976)]. The average value of the exponent for the threshold studies is .11 , as compared with .12 for the nonmetrically analyzed suprathreshold experiments. Note that these exponent values are approximately half as large as those estimated from straightforward magnitude estimation experiments. Possible reasons for this discrepancy have been discussed elsewhere (Marks, 1974; Schneider et al., 1974; Wagenaar, 1975). The interesting thing to note is that in those cases in which the observer is explicitly asked to compare signals differing in intensity (two-alternative or two-interval forced choice; judgments of loudness differences, similarities, or ratios), the judgments are based on the subtractive difference between power functions of the two intensities in which the exponent of the power transformation is approximately .12.

Falmagne (1974, p. 131) has argued that "a sensory scale should be called a scale of sensation only if it explains a large body of sensory data, collected with a variety of methods." A power function on sound intensity with an exponent near .12 does exactly that for pairs of monaurally presented $1,000-\mathrm{Hz}$ tone bursts. It fails to explain the larger exponents obtained with magnitude estimates or productions of loudness with single stimuli; however, these larger exponents may be due to nonlinearities in the response system relating numbers to loudnesses (Rule, Curtis, \& Markley, 1970; Schneider et al., 1976).

The value of the exponent (.12) should be taken only as an approximation. The wide variation in estimates of this exponent in the experiments reported here may reflect large intersubject differences. Typically, many of the studies reported above employed only one to three subjects. If there is wide variation in the exponent value across subjects, then studies involving only a few subjects may legitimately arrive at different estimates of the exponent. Finally, it is not clear to what extent the exponent of the power function is influenced by experimental parameters such as signal duration, background noise, etc.

The studies reviewed here suggest that Fechner's assumption is indeed consistent with a power function representation for loudness. According to the favored model, loudness is a power function of sound intensity. In any task involving (1) discrimination of two tones, (2) judgments of loudness difference, (3) judgments of loudness similarity, (4) paired comparisons of loudness differences, and (5) judgments of loudness ratios (see Schneider et al., 1976), the comparison made between the two tones is based on the subtractive difference of their loudness values. This subtractive difference $(\Delta \mathrm{L})$ is constant at threshold (Fechner's assumption). At suprathreshold levels, stimulus comparisons are based on the loudness difference values of the two stimuli. Thus, according to this model, threshold and suprathreshold judgments reflect the same basic sensory processes.

An important question, which is as yet unanswered, is the extent to which Model 1 (sensory discrimination model) can account for threshold and suprathreshold difference judgments for other sensory continua. The study by Mansfield (1976) suggests that the model may hold under certain conditions for visual brightness. If it can be shown to be widely applicable in both vision and the other senses, then we could conclude that Fechner was correct in assuming that "equally often noticed differences are subjectively equal." Fechner's mistake may not have been in his assumption, but rather in his acceptance of Weber's law.

\section{REFERENCES}

BARLOW, H. B. Increment thresholds at low intensities considered as signal/noise discriminations. Journal of Physiology (London), 1957, 136, 469-488.

BLACKWELL, H. R. Contrast thresholds of the human eye. Journal of the Optical Society of America, 1946, 36, 624-634.

Campbell, R. A., \& Lasky, E. Z. Masker level and sinusoidal signal detection. Journal of the Acoustical Society of America, 1967, 42, 972-976.

Cornsweet, T. N., \& Pinsker, H. M. Luminance discrimination of brief flashes under various conditions of adaptation. Journal of Physiology, 1965, 176, 294-310.

Falmagne, J. C. The generalized Fechner problem and discrimination. Journal of Mathematical Psychology, 1971, 8, 22-43.

Falmagne, J. C. Foundations of Fechnerian psychophysics. In D. H. Krantz, R. C. Atkinson, R. D. Luce, \& P. Suppes (Eds.), Contemporary developments in mathematical psychology (Vol. 2). San Francisco: Freeman, 1974.

Graybill, F. A. An introduction to linear statistical models (Vol. 1). New York: McGraw-Hill, 1961.

Hood, D. C., \& Finkelstein, M. Comparison of changes in 
sensitivity and sensation: Implications for the response-intensity function of the human photopic system. Journal of Experimental Psychology: Human Perception and Performance, 1979, 5, 391-405.

Jesteadt, W., Wier, C. C., \& Green, D. M. Intensity discrimination as a function of frequency and sensation level. Journal of the Acoustical Society of America, 1977, 61, 160-177.

LUCE, R. D., \& GREEN, D. M. A neural timing theory for response times and the psychophysics of intensity. Psychological Review, $1972,79,14-57$.

MANSFIELD, R. J. W. Visual adaptation: Retinal transduction, brightness and sensitivity. Vision Research, 1976, 16, 679-690.

MARKS, L. Stimulus-range, number of categories and form of the category scale. American Journal of Psychology, 1968, 81, 467-479.

MARKS, L. On scales of sensation. Perception \& Psychophysics, 1974, 16, 358-376.

MCGill, W. J. The slope of the loudness function: A puzzle. In H. Gulliksen \& S. Messick (Eds.), Psychological scaling. Theory and application. New York: Wiley, 1960.

MCGILL, W. J. Neural counting mechanisms and energy detection in audition. Journal of Mathematical Psychology, 1967, 3, 351-376.

McGill, W. J., \& Goldberg, J. P. Pure-tone energy discrimination and energy detection. Journal of the Acoustical Society of America, 1968, 44, 576-581. (a)

McGill, W. J., \& GoldberG, J. P. A study of the near-miss involving Weber's law and pure-tone intensity discrimination. Perception \& Psychophysics, 1968, 4, 105-109. (b)

Parker, S., \& Schneider, B. Nonmetric scaling of loudness and pitch using similarity and difference estimates. Perception \& Psychophysics, 1974, 15, 238-242.

Penner, M. M., Leshowitz, B., Cudahy, E., \& Ricard, G. Intensity discrimination for pulsed sinusoids of various frequencies. Perception \& Psychophysics, 1974, 15, 568-570.

Richards, A. M. Non-metric scaling of loudness. I. $1000-\mathrm{Hz}$ tones. Journal of the Acoustical Society of America, 1974, 56, 582-588.

Rule, S. J., Curtis, D. W., \& Markley, R. P. Input and output transformations from magnitude estimation. Journal of Experimental Psychology, 1970, 86, 343-349.

SCHACKNOW, P. N., \& RAAB, D. H. Intensity discrimination of tone bursts and the form of the Weber function. Perception \& Psychophysics, 1973, 14, 449-450.

SCHARF, B., \& Stevens, S. S. The form of the loudness function near threshold. In Proceedings of the 3rd International Congress of Acoustics. Amsterdam: Elsevier, 1961.

Schneider, B., Parker, S., Farkell, G., \& Kanow, G. The perceptual basis of loudness ratio judgments. Perception \& Psychophysics, 1976, 19, 309-320.

Schneider, B., Parker, S., \& Stein, D. The measurement of loudness using direct comparisons of sensory intervals. Journal of Mathematical Psychology, 1974, 11, 259-273.

Stevens, S. S. The surprising simplicity of sensory metrics. American Psychologist, 1962, 17, 29-39.

Stevens, S. S. Psychophysics. New York: Wiley-Interscience, 1975.

VIEMEISTER, N. F. Intensity discrimination of pulsed sinusoids: The effects of filtered noise. Journal of the Acoustical Society of America, 1972, 51, 1265-1269.

WAGENAAR, W. A. Stevens vs. Fechner: A plea for dismissal of the case. Acta Psychologica, 1975, 39, 225-235.

\section{NOTES}

1. The general form of the loudness function can be written $\mathrm{L}=\left(\mathrm{c}^{\prime} l\right)^{\mathrm{m}}$, where $\mathrm{c}^{\prime}$ is a scalar constant. Clearly, then, it is permissible to specify $I$ with respect to some reference intensity, $I_{0}$. In this way, loudness is specified in arbitrary units, since $I / I_{0}$ is a dimensionless variable.
2. For convenience of formulation, we always designate the more intense stimulus as $I_{c}$ and the less intense as $I_{s}$. This corresponds to usual practice in intensity-increment studies. However, it reverses the usual practice in intensity-decrement studies in which the more intense stimulus is called the standard $\left(\mathrm{I}_{\mathrm{s}}\right)$. Also note that all exponents in this paper are applied to sound intensities, not sound pressures.

3. Note that it does not matter whether the minimization is carried out in terms of sound intensity or sound pressure $(\mathrm{P})$, since $\mathrm{I}=\mathrm{cP}^{2}$. To see this, note that by substitution $\Delta \mathrm{L}=\left(\mathrm{I}_{\mathrm{c}} / \mathrm{I}_{\mathrm{o}}\right)^{\mathrm{m}}-$ $\left(1_{s} / I_{o}\right)^{m}=\left(P_{c} / P_{o}\right)^{2 m}-\left(P_{s} / P_{o}\right)^{2 m}$. Hence, the only difference is that the exponent estimated when sound pressure is used will be twice the value of the exponent of sound intensity.

4. In making comparisons across experiments, it is assumed that $\Delta \mathrm{Ls}$ are directly comparable from experiment to experiment. There is some suggestion in the literature that this may not be true when comparisons are made across frequencies. McGill (1967) found the scalar constant, $c^{\prime}$, in $L=c^{\prime} I^{m}$, to be dependent upon tonal frequency, and the Penner, Leshowitz, Cudahy, \& Ricard (1974) data are in accord with this dependency. With the scalar constant included, $\Delta L_{1}=c^{\prime}\left[\left(I_{c} / I_{0}\right)^{m}-\left(I_{s} / I_{o}\right)^{m}\right]$. Hence, without the rough constancy of $c^{\prime}$, relations involving several $\Delta \mathrm{L}_{\mathrm{t}} \mathrm{s}$ (such as that in Figure 3) cannot be sensibly discussed. Note that $c^{\prime}$ cannot be estimated in Equation 10 since it cancels out in the ratio $(\Sigma \Delta L)^{2}$ / $\left(\mathrm{n} \Sigma \Delta \mathrm{L}^{2}\right)$. Finally, it should be noted that there are two ways in which the size of $\Delta \mathrm{L}_{\text {, }}$ can vary within or across experiments. First, the acuity of the subject could vary. This would be reflected in the size of the difference between $I_{c}$ and $I_{S}$ with a larger difference producing a larger $\Delta \mathrm{L}_{\mathrm{t}}$ for a fixed value of the exponent, $m$. Second, for fixed $\mathrm{I}_{\mathrm{c}}$ and $\mathrm{I}_{s}, \Delta \mathrm{L}_{\mathrm{t}}$ will depend on the size of the exponent, $m$. Hence, $\Delta \mathrm{L}_{\mathrm{t}}$ reflects the operation of both of these factors.

5. As in the case of Model 1, it can be shown that, for Model 2, it does not make any difference whether pressure or intensity is used in the minimization process. If pressure is used, the recovered exponent will be twice the value of the exponent for intensity. Also note that $\Delta R$, like $\Delta \mathrm{L}$, is the same whether expressed in intensity or pressure units.

6. If an equivalent analysis is carried out for both Model 1 and Model 2 with stimuli less than $30 \mathrm{~dB}$, the results are comparable to those reported here. The exponent values ranged from .05 to .15 , with a mean of .10 . With the exception of the McGill and Goldberg (1968a) study, the results for Model 2 were essentially unchanged. Exponents ranged from .05 to .13 , with a mean of .10 . However, for the McGill and Goldberg (1968a) data, the estimated exponent was only .10, as compared with the exponent of .75 (see Table 3) found for the data above $30 \mathrm{~dB}$. Hence, the anomalous exponent shown in Table 3 for this study disappears when the full data are analyzed. It should also be noted that, for Model 2, the values of the parameter $k$ for the full data were quite different from the values of that parameter when only the data above $30 \mathrm{~dB}$ are considered. The probable reason for this is discussed in Footnote 7 .

7. The reason the two models can make similar predictions is as follows. Consider the ratio of $\hat{\mathrm{I}}_{c}$ for Model 1 to $\hat{\mathrm{I}}_{\mathrm{c}}$ for Model 2 . This ratio is $\left[\Delta L+\left(I_{s} / I_{o}\right)^{m_{1}}\right]^{1 / m_{1}} /\left\{10^{\Delta R}\left[\left(I_{s} / I_{o}\right)^{m_{2}}+k\right]-k\right\}^{1 / m_{2}}$. If $m_{1}$ $=\mathrm{m}_{2}$, as it does for most of the studies reported here, this ratio becomes $\left[\left(\mathrm{I}_{\mathrm{s}} / \mathrm{I}_{\mathrm{o}}\right)^{\mathrm{m}}+\Delta \mathrm{L}\right] /\left[10^{\Delta \mathrm{R}}\left(\mathrm{I}_{\mathrm{s}} / \mathrm{I}_{\mathrm{o}}\right)^{\mathrm{m}}+\mathrm{k}\left(10^{\Delta \mathrm{R}}-1\right)\right]$. For $10^{\Delta \mathrm{R}}$ close to 1.0 and $k\left(10^{\Delta R}-1\right) \cong \Delta L$, the two terms will have similar values. Substituting from Equation 6,

$$
k\left(10^{\Delta \mathrm{R}}-1\right)=k\left\{\prod_{i=1}^{n}\left[\left(\left(I_{\mathrm{ci}} / \mathrm{I}_{\mathrm{o}}\right)^{\mathrm{m}}+\mathrm{k}\right) /\left(\left(\mathrm{I}_{\mathrm{si}} / \mathrm{I}_{\mathrm{o}}\right)^{\mathrm{m}}+\mathrm{k}\right)\right]^{1 / \mathrm{n}}-1\right\} .
$$

When $k=0$, this function equals zero. For $k>0$, the value of this function increases. It can be shown that a lower bound for this function is $\left[\left(I_{c L} / I_{o}\right)^{m}-\left(I_{s L} / I_{o}\right)^{m}\right] /\left[\left(I_{s L} / I_{o}\right)^{m} / k+1\right]$, where $\left(I_{c L} / I_{o}\right)^{m}$ $-\left(I_{S t} / I_{0}\right)^{m}$ is the smallest power function intensity difference in the threshold study, and that an upper bound is $\left[\left(\mathrm{I}_{\mathrm{cu}} / \mathrm{I}_{\mathrm{o}}\right)^{\mathrm{m}}\right.$ 
$\left.\left(I_{s u} / I_{o}\right)^{m}\right] /\left[\left(I_{s u} / I_{o}\right)^{m} / k+1\right]$, where $\left(I_{c u} / I_{o}\right)^{m}-\left(I_{s u} / I_{o}\right)^{m}$ is the largest such difference. As $k \rightarrow \infty$, the lower bound approaches $\left(I_{c L} / I_{o}\right)^{m}-\left(I_{s L} / I_{o}\right)^{m}$ and the upper bound approaches $\left(I_{c u} / I_{o}\right)^{m}-$ $\left(I_{s u} / I_{o}\right)^{m}$. Note that these lower and upper bounds on $\mathrm{k}\left(10^{\Delta R}-1\right)$ for the large $k$ bracket our estimate of $\Delta \mathrm{L}$ which is $(1 / \mathrm{n}) \Sigma\left[\left(\mathrm{I}_{\mathrm{ci}} / \mathrm{I}_{\mathrm{o}}\right)^{\mathrm{m}}\right.$ - $\left.\left(\mathrm{I}_{\mathrm{si}} / \mathrm{I}_{\mathrm{o}}\right)^{\mathrm{m}}\right]$. Hence, as $\mathrm{k}$ is increased from zero, it should be possible to find a value of $k$ such that $k\left(10^{\Delta R}-1\right) \cong \Delta L$. If the value of $k$ which does this is large, then $10^{\Delta R}\left(I_{s} / I_{o}\right)^{m} \cong\left(I_{s} / I_{o}\right)^{m}$ and the two models will make identical predictions. In the experiments reported here, with the exception of McGill and Goldberg (1968a), such an equivalence did indeed occur. Hence, it is not surprising that $k$ varied as widely as it did, since the expression $k\left(10^{\Delta R}-1\right)$ approaches asymptotic value rather slowly.

8. To see this, it is necessary only to divide through both sides of Equation 17 by $I^{\mathrm{n}}$ and rearrange terms so that the equation now reads $\left\{\left[k(\pi) I^{n-1}+1\right]^{n}-1\right\} /\left\{\left[k\left(\pi^{\prime}\right) I^{n-1}+1\right]^{n}-1\right\}=k(\pi) / k\left(\pi^{\prime}\right)$. Notice that the left side of the equation must equal $k(\pi) / k\left(\pi^{\prime}\right)$. If the left side must equal a constant, then the derivative of the left side with respect to I must equal zero. Setting the derivative of the left side equal to zero results in the requirement that $\left\{\left[k(n) I^{n-1}+1\right]^{n}\right.$ $-1\} /\left\{\left[k\left(\pi^{\prime}\right) I^{n-1}+1\right]^{n}-1\right\}=\left\{k(\pi)\left[k(\pi) I^{n-1}+1\right]^{n-1}\right\} /\left\{k\left(\pi^{\prime}\right)\left[k\left(\pi^{\prime}\right) I^{n-1}\right.\right.$ $\left.+1]^{n-1}\right\}$. Both of these equations can be true only if $\left[k(n) I^{n-1}\right.$ $+1]^{n-1}=\left[k\left(\pi^{\prime}\right) I^{n-1}+1\right]^{n-1}$. This, in turn, can be true only for $\mathrm{n}=1$, or $\mathrm{k}\left(\pi^{\prime}\right)=\mathrm{k}(\pi)$.

(Received for publication October 15, 1979; revision accepted July $15,1980$. ) 